\title{
Diagnosis of hemochromatosis in family members of probands: A comparison of phenotyping and HFE genotyping
}

\author{
James C. Barton, $M D^{1}$, Barry E. Rothenberg, PhD', Luigi F. Bertoli, $M D^{1}$, and Ronald T. Acton, $P h D^{3}$
}

\begin{abstract}
Purpose: We wanted to compare phenotyping and HFE genotyping for diagnosis of hemochromatosis in 150 family members of 61 probands. Methods: Phenotypes were defined by persistent transferrin saturation elevation, iron overload, or both; genotypes were defined by HFE mutation analysis. Results: Twenty-five family members were $\mathrm{C} 282 \mathrm{Y}$ homozygotes; 23 of these (92\%) had a hemochromatosis phenotype. Twenty-three family members had HFE genotype $\mathrm{C} 282 \mathrm{Y} / \mathrm{H63D}$; eight of these (35\%) had a hemochromatosis phenotype. Six of $102(6 \%)$ family members who inherited other HFE genotypes had a hemochromatosis phenotype. Conclusion: Phenotyping and genotyping are complementary in diagnosing hemochromatosis among family members of probands. Genetics in Medicine, 1999; 1(3):89-93
\end{abstract}

Key words: hemochromatosis, iron overload, HFE mutation, genetic counseling

\section{INTRODUCTION}

Hemochromatosis is an autosomal recessive disorder that affects approximately $0.5 \%$ of Caucasians of European descent. ${ }^{1,2}$ Iron absorption in homozygotes is inappropriately high for body iron content, and many subjects have progressive iron deposition that causes injury to the liver, joints, pancreas, heart, and other organs. ${ }^{2}$ Two hemochromatosis-associated mutations in the HFE gene on chromosome $6 \mathrm{p}$ have been identified: cDNA nucleotide $845 \mathrm{G} \rightarrow \mathrm{A}(\mathrm{C} 282 \mathrm{Y})$ and $187 \mathrm{C} \rightarrow \mathrm{G}(\mathrm{H} 63 \mathrm{D}) .{ }^{3}$ These mutations do not occur simultaneously on the same chromosome. ${ }^{3-5}$ To assess HFE genotyping of family members of hemochromatosis probands as a means to identify persons with a hemochromatosis phenotype or to assess their risk for iron overload, we performed a prospective analysis of probands and their family members who volunteered to undergo clinical assessments for phenotypic evidence of hemochromatosis and HFE mutation analysis.

\section{PATIENTS AND METHODS}

\section{Identification of probands and family members}

The performance of this study was approved by the Research and Human Use Committees of Brookwood Medical Center and the University of Alabama at Birmingham. We identified consecutive hemochromatosis probands diagnosed during routine medical care delivery from June 1996 to June 1998. After appropriate genetic counseling, probands and family members were offered the opportunity to undergo testing for $H F E$ gene mutations and clinical laboratory assessments as a part of a research protocol. No relatives of probands were diagnosed to have hemochromatosis before their entry into this study. All

From the 'Southern Iron Disorders Center and Brookwood Medical Center, Birmingham, Alabama; ${ }^{2}$ Billups-Rothenberg, Inc., San Diego, California; and ${ }^{3}$ Immunogenetics Program, and Departments of Microbiology, Epidemiology, and Medicine, University of Alabama at Birmingham

Address correspondence to: Dr. James C. Barton, Southern Iron Disorders Center, Suite G-105, 2022 Brookwood Medical Center Drive,Birmingham, AL 35209; E-mail: ironmd@mem.po.com

March/April 1999 - Vol. $1 \cdot$ No. 3 persons who participated were Caucasians and were volunteers, but were not otherwise selected. All probands were adults ( $\geq 18$ years of age); all family members (except an 11-year-old boy) were also adults. We tabulated data on all evaluable family members and their corresponding probands.

\section{Diagnosis of hemochromatosis and evaluation of iron overload Probands}

Each proband was diagnosed and evaluated for iron overload as previously described. ${ }^{6}$ We used the working diagnostic criterion for hemochromatosis of the American College of Pathologists: elevated fasting transferrin saturation ( $\geq 60 \%$ males, $\geq 50 \%$ females) on at least two occasions in the absence of other known causes. ${ }^{2}$ Iron overload was defined as evidence of systemic iron overload demonstrated by otherwise unexplained elevated serum ferritin concentration ( $\geq 300 \mathrm{ng} / \mathrm{mL}$ in men, $\geq 200 \mathrm{ng} / \mathrm{mL}$ in women), increased hepatic iron content determined using hepatic biopsy specimens, or iron $\geq 4 \mathrm{~g}$ mobilized by phlebotomy ${ }^{5-7}$ Concentrations of serum ferritin used in this paper to diagnose iron overload are based on current recommendations for initiating phlebotomy treatment for hemochromatosis. ${ }^{8}$ Genetic criteria were not used to establish the diagnosis of hemochromatosis in probands.

\section{Family members}

In family members, a hemochromatosis phenotype was defined as the presence of elevated transferrin saturation or iron overload or both (as described above). Blood specimens for analysis of serum iron parameters (serum transferrin saturation, serum ferritin concentration) and HFE genotype were drawn simultaneously in each family member who volunteered to participate in this study. Family members who had abnormal serum iron parameters underwent subsequent clinical evaluations similar to those of probands..$^{5-7}$ In all subjects, serum iron parameters, general clinical evaluation, and analysis of the HFE mutant alleles (C282Y and H63D) and wild-type (wt) allele were performed as previously described. ${ }^{5}$ 


\section{Statistical considerations}

Our data set consisted of observations of 61 probands and 150 family members. Thirty-five additional probands were diagnosed during the study interval. They had similar clinical phenotypes and HFE genotypes to those of the 61 probands described herein but were not included because they had no family members who volunteered for evaluation. Descriptive data are presented as percentages or means $\pm 1 \mathrm{SD}$; statistical comparisons were performed using chi-square analysis.

\section{RESULTS}

\section{Relationship of hemochromatosis phenotype and HFE genotype}

Probands

Among 61 probands, $42(68.9 \%)$ were men and $19(31.1 \%)$ were women (Table 1). The mean age of the 61 probands was 54 \pm 13 years. Of all probands, $51(83.6 \%)$ had two HFE mutations, $7(11.5 \%)$ had a single HFE gene mutation, and $3(4.9 \%)$ had no detectable HFE mutation. These frequencies are similar to those previously reported in hemochromatosis probands from our geographic area. ${ }^{5}$ All of our probands had iron overload. Ten $(16.4 \%)$ had hepatic cirrhosis and three $(4.9 \%)$ had diabetes mellitus attributed to iron overload; each of these probands was homozygous for the $\mathrm{C} 282 \mathrm{Y}$ mutation. In aggregate, iron overload was more severe among probands who were $\mathrm{C} 282 \mathrm{Y}$ homozygotes than among probands who had other HFE genotypes. ${ }^{5,9-11}$

\section{Family members}

Among 150 family members, 72 (48.0\%) were men and 78 $(52.0 \%)$ were women; the mean age of the family members was $46 \pm 15$ years. Thirty-four of $150(22.7 \%)$ had a hemochromatosis phenotype and 60 of $150(40.0 \%)$ had two HFE mutations (Tables 2 and 3). Among 94 first-degree family members (parents, children, siblings), 30 (31.9\%) had a hemochromatosis phenotype. Among 56 non-first-degree family members, four $(7.1 \%)$ had a hemochromatosis phenotype. Altogether, 30 of 34 $(88.2 \%)$ family members with a hemochromatosis phenotype were first-degree relatives of probands.

Twenty-five family members were homozygous for the C282Y mutation. Each of these was a blood relative of the proband, and 14 of $25(56.0 \%)$ were siblings of probands (Table 2). A hemochromatosis phenotype was detected in 23 of $25(92.0 \%)$ C282Y homozygous family members; two family members $(8.0 \%)$ had hepatic cirrhosis; and four family members (16.0\%) had diabetes mellitus attributed to iron overload. However, two $\mathrm{C} 282 \mathrm{Y}$ homozygotes $(8.0 \%)$ had no phenotypic evidence of hemochromatosis and were detected only by HFE genotyping: the 11-year-old nephew of one proband and the 32-year-old sister of another proband (Table 3 ).

Twenty-three family members were $\mathrm{C} 282 \mathrm{Y} / \mathrm{H} 63 \mathrm{D}$ compound heterozygotes, $8(34.5 \%)$ were siblings of probands, and $3(7.9 \%)$ were spouses or other relatives by marriage (Table 2). Eight of

Table 1

HFE genotypes of 61 hemochromatosis probands

\begin{tabular}{lccccc}
\hline HFE genotype & Men, $\mathrm{n}(\%)$ & Women, $\mathrm{n}(\%)$ & All probands, $\mathrm{n}(\%)$ & Serum Ferritin, $\mathrm{ng} / \mathrm{mL}$ & $\begin{array}{c}\text { Probands who had } \\
\text { blood relatives with a } \\
\text { hemochromatosis } \\
\text { phenotype, } \mathrm{n}(\%)\end{array}$ \\
\hline $\mathrm{C} 282 \mathrm{Y} / \mathrm{C} 282 \mathrm{Y}$ & $29(69.0)$ & $16(84.2)$ & $45(73.8)$ & $1516 \pm 1443$ & $16(35.6)$ \\
$\mathrm{C} 282 \mathrm{Y} / \mathrm{H} 63 \mathrm{D}$ & $6(14.3)$ & $0(0)$ & $6(9.8)$ & $493 \pm 563$ & $5(83.3)$ \\
$\mathrm{H} 63 \mathrm{D} / \mathrm{H} 63 \mathrm{D}$ & $0(0)$ & $0(0)$ & $0(0)$ & - & - \\
$\mathrm{C} 282 \mathrm{Y} / \mathrm{wt}$ & $5(11.9)$ & $1(5.3)$ & $6(9.8)$ & $711 \pm 346$ & 0 \\
$\mathrm{H} 63 \mathrm{D} / \mathrm{wt}$ & $1(2.4)$ & $0(0)$ & $1(1.6)$ & 755 & 0 \\
$\mathrm{wt} / \mathrm{wt}$ & $1(2.4)$ & $2(10.5)$ & $3(5.0)$ & $2261 \pm 2849$ & $1(100)$ \\
Total & $42(100)$ & $19(100)$ & $61(100)$ & $1358 \pm 1437$ & $22(361)$ \\
\hline${ }^{a} \mathrm{C} 282 \mathrm{Y}$ &
\end{tabular}

${ }^{a} \mathrm{C} 282 \mathrm{Y}$, cDNA nucleotide $845 \mathrm{G} \rightarrow \mathrm{A} ; \mathrm{H} 63 \mathrm{D}, \mathrm{cDNA}$ nucleotide $187 \mathrm{C} \rightarrow \mathrm{G}$; wt, wild-type (normal) HFE allele.

Table 2

HFE genotypes of 150 family members of 61 hemochromatosis probands

\begin{tabular}{lccccc}
\hline HFE genotype & Siblings, $\mathrm{n}(\%)$ & Parents, $\mathrm{n}(\%)$ & Offspring, $\mathrm{n}(\%)$ & $\begin{array}{c}\text { Other blood } \\
\text { relatives, } \mathrm{n}(\%)^{\mathrm{h}}\end{array}$ & $\begin{array}{c}\text { Spouses, other relatives } \\
\text { by marriage, } \mathrm{n}(\%)^{\mathrm{c}}\end{array}$ \\
\hline $\mathrm{C} 282 \mathrm{Y} / \mathrm{C} 282 \mathrm{Y}$ & $14(33.3)$ & $3(18.8)$ & $5(13.9)$ & $3(16.7)$ & $0(0)$ \\
$\mathrm{C} 282 \mathrm{Y} / \mathrm{H} 63 \mathrm{D}$ & $8(19.0)$ & $5(31.2)$ & $5(13.9)$ & $2(11.1)$ & $3(7.9)$ \\
$\mathrm{H} 63 \mathrm{D} / \mathrm{H} 63 \mathrm{D}$ & $1(2.4)$ & $0(0)$ & $1(2.8)$ & $9(50.0)$ & $1(2.6)$ \\
$\mathrm{C} 282 \mathrm{Y} / \mathrm{wt}$ & $11(26.2)$ & $7(43.8)$ & $22(61.0)$ & $3(16.7)$ & $9(23.7)$ \\
$\mathrm{H} 63 \mathrm{D} / \mathrm{wt}$ & $2(4.8)$ & $0(0)$ & $2(5.6)$ & $1(5.5)$ & $3(7.9)$ \\
$\mathrm{wt} / \mathrm{wt}$ & $6(14.3)$ & $1(6.2)$ & $1(2.8)$ & $0(0)$ & $22(57.9)$ \\
Total & $42(100)$ & $16(100)$ & $36(100)$ & $18(100)$ & $38(100)$ \\
\hline
\end{tabular}

${ }^{\circ} \mathrm{C} 282 \mathrm{Y}, \mathrm{cDNA}$ nucleotide $845 \mathrm{G} \rightarrow \mathrm{A}$; H63D, cDNA nucleotide $187 \mathrm{C} \rightarrow \mathrm{G}$; wt, wild-type (normal) HFE allele.

${ }^{b}$ Includes grandparents, grandchildren, aunts, uncles, nieces, nephews, and cousins.

'Includes parents-, children-, brothers-, and sisters-in-law. 
Table 3

Clinical phenotypes and HFE genotypes of 150 family members of 61 hemochromatosis probands

\begin{tabular}{lcccc}
\hline HFE genotypec $(\mathrm{n} ; \mathrm{M}, \mathrm{F})$ & $\begin{array}{c}\text { Age, } \mathrm{yr} \\
\text { (mean } \pm \mathrm{I} \text { S.D.) }\end{array}$ & $\begin{array}{c}\text { Elevated transferrin } \\
\text { saturation, } \mathrm{n}(\%)\end{array}$ & $\begin{array}{c}\text { Iron overload, } \\
\mathrm{n}(\%)\end{array}$ & $\begin{array}{c}\text { No phenotypic evidence } \\
\text { of hemochromatosis, } \\
\mathrm{n}(\%)\end{array}$ \\
\hline $\mathrm{C} 282 \mathrm{Y} / \mathrm{C} 282 \mathrm{Y}(25 ; 14,11)$ & $45 \pm 15$ & $21(84.0)^{d}$ & $23(92.0)^{d}$ & $2(8.0)$ \\
$\mathrm{C} 282 \mathrm{Y} / \mathrm{H} 63 \mathrm{D}(23 ; 14,9)$ & $48 \pm 11$ & $8(34.8)$ & $7(30.4)$ & $15(65.2)$ \\
$\mathrm{H} 63 \mathrm{D} / \mathrm{H} 63 \mathrm{D}(12 ; 4,8)$ & $49 \pm 11$ & 0 & 0 & 0 \\
$\mathrm{C} 282 \mathrm{Y} / \mathrm{wt}(52 ; 22,30)$ & $53 \pm 9$ & $4(7.7)$ & $2(3.8)$ & $48(92.3)$ \\
$\mathrm{H} 63 \mathrm{D} / \mathrm{wt}(8 ; 4,4)$ & $51 \pm 7$ & $2(25.0)$ & $2(25.0)$ & $6(75.0)$ \\
$\mathrm{wt} / \mathrm{wt}(30 ; 14,16)$ & $47 \pm 10$ & $1(3.3)$ & 0 & $29(96.7)$ \\
\hline
\end{tabular}

"C282Y, cDNA nucleotide $845 \mathrm{G} \rightarrow \mathrm{A} ; \mathrm{H} 63 \mathrm{D}, \mathrm{cDNA}$ nucleotide $187 \mathrm{C} \rightarrow \mathrm{G}$; wt, wild-type (normal) HFE allele.

"Evidence of systemic iron overload demonstrated by otherwise unexplained elevated serum ferritin concentration, increased hepatic iron content, or iron mobilized by phlebotomy of $\geq 4 \mathrm{~g}$.

"No evidence of elevated transferrin saturation or systemic iron overload as defined above.

"Two unrelated women who were C282Y homozygotes had serum ferritin concentrations $>300 \mathrm{ng} / \mathrm{mL}$ associated with transferrin saturation values of $35 \%-47 \%$; both had iron overload demonstrated by therapeutic phlebotomy.

$23(34.8 \%)$ family members who were $\mathrm{C} 282 \mathrm{Y} / \mathrm{H} 63 \mathrm{D}$ compound heterozygotes had a hemochromatosis phenotype $(6$ men, 2 women). This frequency of hemochromatosis phenotypes was significantly less than that observed among family members who were $\mathrm{C} 282 \mathrm{Y}$ homozygotes $(34.8 \%$ vs. $92.0 \%$, respectively; $\mathrm{P}<0.01)$. Furthermore, no $\mathrm{C} 282 \mathrm{Y} / \mathrm{H} 63 \mathrm{D}$ compound heterozygotes had hepatic cirrhosis or diabetes mellitus, and iron overload was generally less severe in these family members than among those who had a hemochromatosis phenotype associated with C282Y homozygosity. ${ }^{5,9-11}$ Fifteen of 23 (65.2\%) who were $\mathrm{C} 282 \mathrm{Y} / \mathrm{H} 63 \mathrm{D}$ compound heterozygotes had no phenotypic evidence of hemochromatosis ( 8 men, 7 women).

Among 12 family members who were H63D homozygotes, none had a hemochromatosis phenotype. Sixty family members were heterozygous for $\mathrm{C} 282 \mathrm{Y}$ or $\mathrm{H} 63 \mathrm{D}$ mutations; six ( $10.0 \%$ ) had a hemochromatosis phenotype ( 4 men, 2 women), but none had hepatic cirrhosis or diabetes mellitus attributed to iron overload (Tables 2 and 3). Thirty family members had no detectable HFE mutant alleles, and none had iron overload. However, the 48-year-old female monozygotic twin of a proband had only persistently elevated values of transferrin saturation (her twin sister had elevated transferrin saturation and iron overload). Taken together, only 4 of 102 (3.9\%) family members who had H63D/H63D, C282Y/wt, or H63D/wt genotypes had iron overload (Table 3 ).

\section{HFE genotypes and pseudodominant patterns of hemochromatosis inheritance}

We observed persons in successive generations who inherited two HFE mutations in 12 kinships; in eleven of these, we also identified a hemochromatosis phenotype in persons of successive generations. We tested the spouses of 20 probands. Eight spouses (40.0\%) had one or more mutant HFE alleles; this percentage is similar to the frequency of persons in the general Caucasian population in our geographic area who have one or more HFE mutations ( 54 of $143 ; 37.8 \%) .{ }^{5}$ In five of the eight corre-

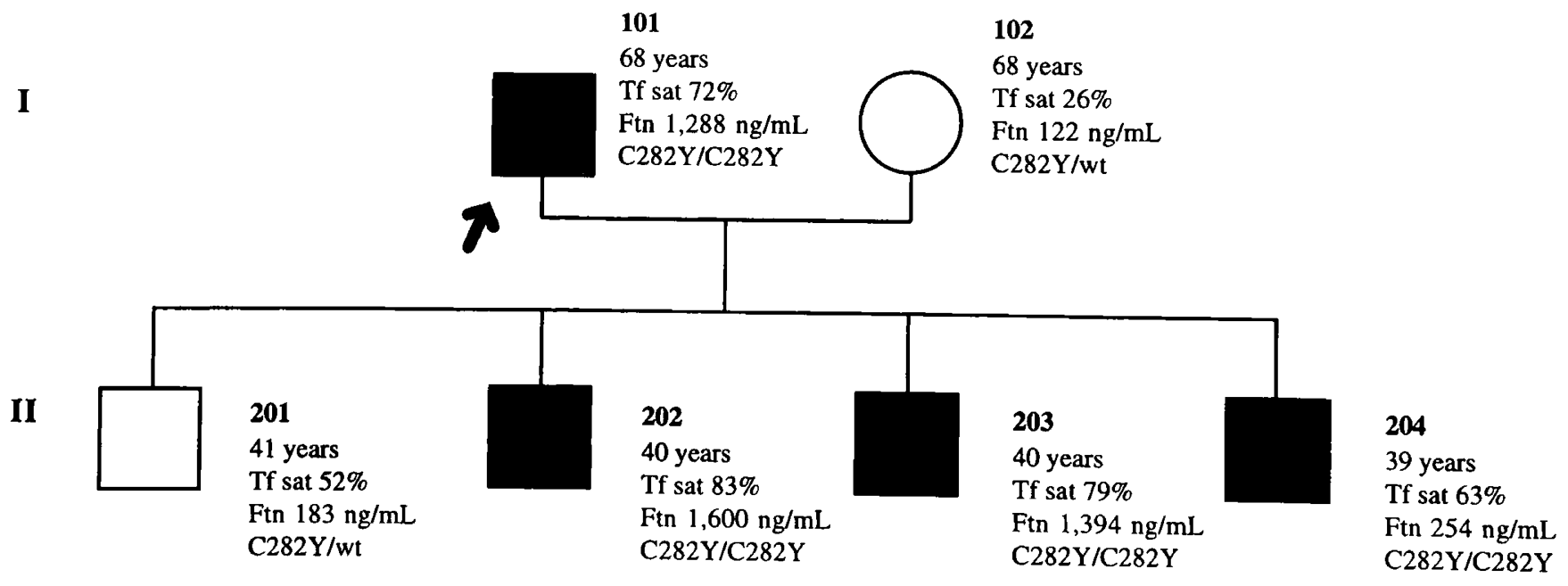

Fig. 1 This pedigree illustrates the mating of a C282Y homozygote and a C282Y heterozygote. $\square=$ male, $\bullet=$ female, $\varnothing=$ deccased, $\mathbf{m}=$ hemochromatosis phenotype. The proband is indicated by an arrow. Phenotype and genotype data: age at diagnosis or evaluation, years; Tf sat, transferrin saturation, \%; Ftı, serum ferritin concentration, ng/mL; C282Y, cDNA nucleotide $845 \mathrm{G} \rightarrow \mathrm{A} ; \mathrm{H} 63 \mathrm{D}$, cDNA nucleotide $187 \mathrm{C} \rightarrow \mathrm{G}$; wt, wild-type (normal) HFE allele. C282Y, H63D, and wt alleles are known to exist only on separate chromosomes. 
sponding kinships, we also tested one or more offspring. In each of the five kinships, we identified offspring who inherited two mutant HFE alleles and also had a hemochromatosis phenotype. Among the kinships, we identified five additional spouse pairs who had untested offspring at risk to have C282Y homozygosity; four spouse pairs had untested offspring at risk to have C282Y/H63D compound heterozygosity. Different HFE genotypes within the same kinship, usually C282Y homozygosity and C282Y/H63D compound heterozygosity, were associated with a hemochromatosis phenotype in two or more persons in each of seven kinships. Pedigrees of our families revealed several combinations of HFE genotypes in successive generations that were associated with hemochromatosis phenotypes; two pedigrees are depicted in Figures 1 and 2.

\section{DISCUSSION}

Our results confirm that hemochromatosis phenotypes and abnormal $H F E$ genotypes are common among family members of probands, especially first-degree relatives. ${ }^{1,2}$ The frequency of hemochromatosis phenotypes among our C282Y homozygous family members was particularly high, consistent with previous observations in other $\mathrm{C} 282 \mathrm{Y}$ homozygotes. ${ }^{5,9-11} \mathrm{HFE}$ genotyping identified two $\mathrm{C} 282 \mathrm{Y}$ homozygotes (a prepubertal boy and a premenopausal woman) who did not have a hemochromatosis phenotype. This is in accordance with observations that the frequency of clinical expression of hemochromatosis is lower in children and premenopausal women than in men who are middle-age or older. ${ }^{1,2}$ The C282Y/H63D genotype is associated with a relatively low frequency of clinical expression of hemochromatosis, ${ }^{5,9-11}$ and iron overload in persons with this genotype is usually of mild or moderate severity. ${ }^{3-5,9-11}$ Our observations in family members of probands corroborate these reports. Whether our family members without a hemochromatosis phenotype, especially those who are $\mathrm{C} 282 \mathrm{Y}$ homozygotes or $\mathrm{C} 282 \mathrm{Y} / \mathrm{H} 63 \mathrm{D}$ compound heterozygotes, will eventually develop clinical evidence of hemochromatosis cannot be determined by our study. However, we recommend that persons with these genotypes undergo measurement of serum iron parameters every 1 to 2 years. If serum ferritin concentrations or other clinical parameters indicate that (even mild) iron overload has developed, treatment with phlebotomy and other measures should be initiated. ${ }^{8}$

Most persons with a hemochromatosis phenotype inherit two mutant HFE alleles. ${ }^{3-5,9-12}$ Accordingly, HFE mutation analysis of family members of hemochromatosis probands can reveal various genotypes and their associated risks for the development of phenotypic evidence of hemochromatosis. Detecting C282Y homozygosity (or C282Y/H63D compound heterozygosity) in children and young adults who are relatives of probands and applying estimates of penetrance of these genotypes ${ }^{3-5,9-12}$ can help predict their future likelihood of developing phenotypic evidence of hemochromatosis that will require phlebotomy therapy to prevent iron overload. Furthermore, our observations using HFE mutation analysis confirm and extend the

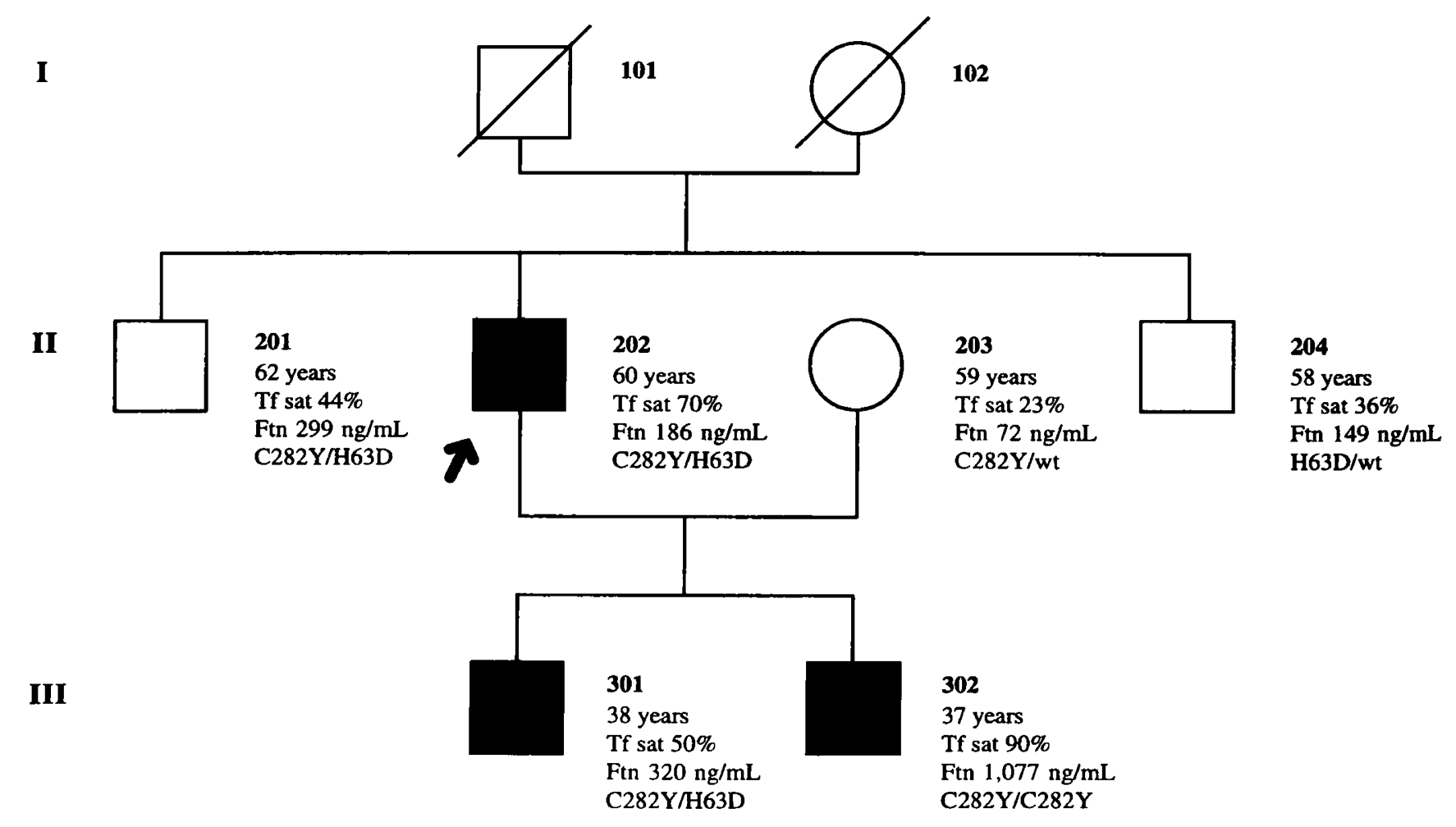

Fig. 2 This pedigree illustrates the mating of a $\mathrm{C} 282 \mathrm{Y} / \mathrm{H} 63 \mathrm{D}$ compound heterozygote and a $\mathrm{C} 282 \mathrm{Y}$ heterozygote. $\square=$ male, $\bullet=$ female, $\varnothing=$ deceased, $\bullet=$ hemochromatosis phenotype. The proband, indicated by an arrow, had chronic gastrointestinal blood loss due to ulcerative colitis. Phenotype and genotype data: age at diagnosis or evaluation, years; Tf sat, transferrin saturation, \%; Ftn, serum ferritin concentration, ng/mL; C282Y, cDNA nucleotide $845 \mathrm{G} \rightarrow \mathrm{A} ; \mathrm{H} 63 \mathrm{D}$, cDNA nucleotide $187 \mathrm{C} \rightarrow \mathrm{G}$; wt, wild-type (normal) HFE allele. C282Y, H63D, and wt alleles are known to exist only on separate chromosomes. 
ability to predict the development of a hemochromatosis phenotype in first-degree relatives of probands based on human leukocyte antigen (HLA) typing. ${ }^{13}$ HFE genotyping of probands and family members, especially spouses, also makes it possible to assess risk for the inheritance of HFE alleles in untested relatives or in future offspring. ${ }^{14}$

HFE genotyping could lead to periodic monitoring of serum iron parameters in clinically normal family members some of whom may never develop iron overload or other evidence of hemochromatosis. Contrariwise, probands (and family members) who have one or no detectable HFE mutations can have a hemochromatosis phenotype. ${ }^{15}$ Taken together, only $5.9 \%$ and $3.9 \%$ of family members who had the HFE genotypes H63D/H63D, H63D/wt, C282Y/wt, or wt/wt had elevated transferrin saturation values and iron overload, respectively. This is consistent with other studies in which persons with iron overload were unlikely to have these HFE genotypes. ${ }^{3-5,9-12}$ Although these frequencies $(5.9 \%$ and $3.9 \%$ ) are approximately 10 -fold greater than the prevalence of hemochromatosis in the general Caucasian population, ${ }^{1,2}$ our data suggest that phenotypic tests of iron metabolism are more specific for hemochromatosis in persons with these HFE genotypes (and other family members predicted to have the same HFE genotypes). Because hemochromatosis is common, involves multiple recessive mutations, and has a variable phenotype, phenotyping and genotyping are complementary in screening for hemochromatosis among family members of probands. Furthermore, HFE mutations other than $\mathrm{C} 282 \mathrm{Y}$ and $\mathrm{H} 63 \mathrm{D}$ have been identified recently, ${ }^{16,17}$ and it seems likely that these and additional future discoveries will explain why hemochromatosis phenotypes sometimes appear among persons who are heterozygous (or negative) for $\mathrm{C} 282 \mathrm{Y}$ or $\mathrm{H} 63 \mathrm{D}$.

\section{References}

1. Edwards CQ, Griffen LM, Goldgar D, Drummond C, Skolnick MH, Kushner JP. Prevalence of hemochromatosis among 11,065 presumably healthy blood donors. $N$ Engl JMed 1988;318:1355-1362.
2. Witte DL, Crosby WH, Edwards CQ, Fairbanks VF, Mitros FA. Practice parameter for hereditary hemochromatosis. Clin Chim Acta 1996;245:139-200.

3. Feder JN, Gnirke A, Thomas W, Tsuchihashi Z, Ruddy DE, Basava A, Dormishiam F, Domingo R, Ellis MC, Fullan A, Hinton LM, Jones NL, Kimmel BE, Kronmal GS, Lauer P, Lee VK, Loeb DB, Mapa FA, McClelland E, Meyer NC, Mintier GA, Moeller N, Moore T, Morikang E, Prass CE, Quintana L, Starnes SM, Schatzman RC, Brunke $\mathrm{KJ}$, Crayna DT, Risch NJ, Bacon BR, Wolff RK. A novel MHC class-I-like gene is mutated in patients with hereditary hemochromatosis. Nat Genet 1996;14:399-408.

4. Beutler E, Gelbart T, West C, Lee P, Adams M, Blackstone R, Pockros P, Kosty M, Venditti CP, Phathak PD, Seese NK, Chorney KA, Ten Elshof AE, Gerhard GS, Chorney M. Mutation analysis in hereditary hemochromatosis. Blood Cells Mol Dis 1996;22:187-194.

5. Barton IC, Shih WWH, Sawada-Hirai R, Acton RT, Harmon L, Rivers C, Rothenberg $\mathrm{BE}$. Genetic and clinical description of hemochromatosis probands and heterozygotes: evidence that multiple genes linked to the major histocompatibility complex are responsible for hemochromatosis. Blood Cells Mol Dis 1997;23:135-145.

6. Barton JC, Barton NH, Alford TJ. Diagnosis of hemochromatosis in a community hospital. Am J Med 1997;103:498-503.

7. Barton IC, Harmon L, Rivers C, Acton RT. Hemochromatosis: Association of severity of iron overload with genetic markers. Blood Cells Mol Dis 1996;22:195-204.

8. Barton IC, McDonnell SE, Adams PC, Brissot P, Powell LW, Edwards CQ, Cook JD, Kowdley KV, Hemochromatosis Management Working Group. Management of hemochromatosis. Ann Intern Med 1998;129:932-939.

9. Mura C, Nousbaum JB, Verger P, Moalic MT, Raguenes O, Mercier AY, Ferec C. Phenotype-genotype correlation in haemochromatosis subjects. Hum Genet 1997;101:27127-6.

10. Sham RL, Ou CY, Cappuccio J, Braggins C, Dunnigan K, Phathak PD. Correlation between genotype and phenotype in hereditary hemochromatosis: analysis of 61 cases. Blood Cell Mol Dis 1997;23:314-320.

11. Adams PC, Chakrabarti S. Genotype/phenotype correlations in genetic hemochromatosis: Evolution of diagnostic criteria. Gastroenterology 1998;114:319-323.

12. Crawford DHG, Jazwinska EC, Cullen LM, Powell LW. Expression of HLA-linked hemochromatosis in subjects homozygous or heterozygous for the $\mathrm{C} 282 \mathrm{Y}$ mutation. Gastroenterology 1998;114:1003-1008.

13. Conte WJ, Rotter JI. The use of association data to identify family members at high risk for marker-linked diseases. Am J Hum Genet 1984;36:152-166.

14. Adams PC. Implications of genotyping of spouses to limit investigation of children in genetic hemochromatosis. Clin Genet 1998;53:176-178.

15. Carella M, D’Ambrosio L, Totaro A, Grifia A, Valentino MA, Piperno A, Girelli D, Roetto A, Franco B, Gasparini P, Camaschella C. Mutation analysis of the HLA-H gene in Italian hemochromatosis patients. Am J Hum Genet 1997;60:828-832.

16. Douabin V, Deugnier Y, Jouanolle AM, Moirand R, Macqueron G, Gireau A, Le Gall $\mathrm{Y}$, David V. Polymorphisms in the haemochromatosis gene. International Symposium on Iron in Biology and Medicine. Saint-Malo, France, June 1998.

17. Bernard PS, Ajioka RS, Kushner JP, Wittwer CT. Homogeneous multiplex genotyping of hemochromatosis mutations with fluorescent hybridization probes. Am J Pathol 1998;153:1055-1061. 